\title{
Innovative scenario planning of petrochemical enterprises in the Iranian community
}

\begin{abstract}
Purpose: Research studies on futures studies have recently gained significant attention to create a desirable future based on the environmental change. Futures studies follow discovery, invention, presentation, test and evolution of possible, feasible and desirable futures. The purpose of this study is to examine some important aspects of the relationship between futures studies and planning and to present a model where futures scenarios have been developed as an integral part of small- and medium-sized enterprises (SMEs) through the lens of dynamic capabilities theory and creative system theory. Design/methodology/approach: Based on interpretive structural modeling and Delphi technique, the most important trends, proponents and uncertainties of the future of 10 Iranian petrochemical SMEs is identified and related innovative scenarios are presented. Findings: The findings show four scenarios on the petrochemical industry including attracting investment, the presence of the private sector, attracting people's capital and sustainable development of the petrochemical industry. Originality/value: The paper undertakes a first of its kind cross-disciplinary conceptual analysis to design Innovative Scenario Planning for SMEs. Despite the importance of scenario planning in SMEs, theories for understanding the nexus of entrepreneurial future studies remain underdeveloped. Therefore, there is still a theoretical gap and lack of research; hence, the current study tries to shed light on the topic and fill the gap in the entrepreneurship literature.
\end{abstract}

Keyword: Business; Future studies; Scenario planning; SMEs; Interpretive structural modelling 